\title{
REFORMA E PREVIDÊNCIA SOCIAL: revirando o baú e folheando as páginas da história de uma velha questão que se reveste em um debate sempre atual
}

Francisco Renato Lima ${ }^{1}$

\section{http://dx.doi.org/10.52641/cadcaj.v7i1.640}

\section{Resenha:}

COHN, Amélia. A reforma da previdência social: virando a página da história? São Paulo em Perspectiva, São Paulo, v. 9, n. 4, p. 54-59, 1995.

\section{Um introito}

Sem dúvida, é extremamente complexo definir e negociar um novo padrão de solidariedade social que fundamente um sistema de seguridade social e que consiga associar os modelos contributivo e redistributivo. Não obstante, fugir a esse desafio, submetendo-se cegamente aos ditames econômicos de curto prazo, pode criar a ilusão de se estar virando a página da história quando na realidade se está reeditando a história.

(COHN, 1995, p. 59)

Os sistemas previdenciários na sociedade em geral, independente do país em que se situem, convergem entre si, ao compartilharem do propósito de que é fundamental buscar assistir financeiramente determinada camada da população em situações específicas, como, por exemplo, doenças e invalidez, vivenciadas no mercado de trabalho, visando assegurar proteção e dignidade aos cidadãos, e assim, diminuir os índices de pobreza e desigualdade social.

Sua execução, no Brasil, em especial, se dá a partir de uma contribuição feita diretamente pelos trabalhadores, ou mesmo, os empregadores podem fazê-lo, com desconto direto no salário. Nesse regime de contribuição, fica a cargo do Ministério da Previdência Social, criado em 1974, executar ações de controle e de gerenciamento dos tributos financeiros, por meio de seu órgão subordinado, o Instituto Nacional do Seguro Social (INSS).

À luz desse breve entendimento sobre a importância e, principalmente, do papel social da previdência na construção trabalhista de nosso país, neste estudo, objetivamos resenhar as oportunas reflexões tecidas pela professora Amélia Cohn, no texto: A reforma da previdência social: virando a página da história?, publicado em 1995, na Revista São Paulo em Perspectiva. No referido

\footnotetext{
${ }^{1}$ Doutorando em Linguística pela Universidade Estadual de Campinas (UNICAMP). Mestre em Letras - Estudos da Linguagem (UFPI). Especializações diversas, envolvendo, de modo interdisciplinar, as áreas de Educação, Linguagem, Saúde, Tecnologias e Ensino. Graduado em Pedagogia (UNIFSA) e em Letras - Português/Inglês (IESM). Atualmente, atua como Professor Assistente na Universidade Estadual do Piauí (UESPI). E-mail: fcorenatolima@hotmail.com
} 
texto, a autora, a partir de uma lente história, apresenta-nos uma projeção histórico-social sobre a construção político-social dessa conquista, a partir de algumas pistas, que nos permitem refletir sobre o seu atual estado, considerando os impactos e as repercussões na vida política e social do Brasil.

\section{Reforma da previdência social: um compilado da obra}

$\mathrm{O}$ artigo intitulado: $A$ reforma da previdência social: virando a página da história?, em sua breve estrutura (seis páginas) distribui a discussão a partir dos seguintes tópicos: a) texto introdutório do tema; do qual seguem dois itens, intitulados pela autora, de: b) A previdência social como seguro social; e c) Previdência social e seguridade social. Desses títulos, que dialogam entre si, emergem os pontos centrais do texto, assim, distribuídos, conforme, seguem-se brevemente, resumidos.

Cohn inicia, situando o período histórico onde se estabeleceram as bases de consolidação da previdência social no Brasil, desde a década de 20 do século XX, quando surgem as Caixas de Aposentadoria e Pensão (CPAs), como "embrião" de uma proposta que, na década 30, por iniciativa do Governo de Getúlio Vargas, resultou na criação dos Institutos de Aposentadorias e Pensões (IAPs), órgão que reunia nacionalmente categorias de assalariados, e que constituiu um pontapé inicial para o firmamento de uma política econômica e financeira da sociedade, reunindo diversos setores e categorias profissionais.

Em seu surgimento estava mais voltada para as classes do setor privado, oriundas da zona urbana, uma vez que o setor público já tinha um sistema de proteção social. Sua finalidade foi, portanto, reunir um conjunto de legislações que corroboraram a definição de padrões regulatórios da relação capital/trabalho no país. Isso contribuiu fortemente para a definição de uma legislação trabalhista, que tem como seu apogeu, a criação do salário mínimo, feito histórico, atribuído a figura do então presidente, Getúlio Vargas.

É a partir desse ponto, que a autora trata da previdência social como seguro social, destacando que sua expansão, se deu a partir de dois pontos: i) "o critério de inserção no mercado formal de trabalho como mecanismo básico de definição de direitos sociais"; e ii) "a ordem cronológica de sua implantação pelos diferentes segmentos assalariados em sincronia com a importância dos setores econômicos nos quais esses segmentos estavam inseridos e com capacidade de mobilização e reivindicação por melhores condições de vida e trabalho". Da articulação disso, surge o que Santos (1979). ${ }^{2}$ apud Cohn (1995), chama de cidadania regulada, em um sistema de proteção social

${ }^{2}$ SANTOS, W. G. Cidadania e justiça. Rio de Janeiro: Campus, 1979. 
baseado na meritocracia, eminentemente contributivo e compulsório (DRAIBE, 1993³; ESPINGANDERSEN, 1980 apud COHN, 1995).

Passando pelas transformações estatais, oriundas de um forte regime de capitalização, que se estende até a década de 1960, a previdência social, vista então, como seguro social, conforme se compromete a autora, no subtítulo do texto, passa a ser um mecanismo de captação de recursos individuais dos trabalhadores urbanos assalariados, com a finalidade de investir em atividades fundamentais de implementação do processo de industrialização no qual o país se insere. Isso contribuiu para o investimento em diversos setores estruturantes do Brasil e contribuiu para diminuir uma crise habitacional e combate ao desemprego no pós-guerra.

O funcionamento desse sistema não é linear, está condicionado, no entanto, a relação contribuintes/destinatários, fato que oscilou gradativamente ao longo de sua constituição histórico-social. Ele constituiu-se então, aliando os direitos sociais dos cidadãos com seus vínculos estabelecidos formalmente no mercado de trabalho.

A seguir a discussão, em: Previdência social e seguridade social, Cohn aponta que a previdência social, a saúde e a assistência social se integram como componentes do sistema de seguridade social, a partir de 1988, com a criação da Constituição Federal, a chamada Constituição Cidadã, que estabeleceu como fontes de financiamento: a contribuição sobre a folha de salários; a contribuição sobre o lucro líquido das empresas; a contribuição para financiamento da seguridade; e o PIS/PASEP, destinado a financiar o seguro desemprego.

Com isso, a seguridade social passa a ser obrigatoriamente financiada por toda a sociedade, mediante recursos do orçamento da União, estados, Distrito Federal e municípios. Sua administração cabe ao Poder Público, guiado pelos termos da lei, garantindo o funcionamento e a execução a seus objetivos, com o propósito de que ela alcance a população, como mecanismo de universalidade de direitos sociais, na prestação se serviços e benefícios, garantindo assim, a participação e a democracia na distribuição dos recursos recolhidos no país.

Uma reflexão oportuna desse ponto, pode ser feita quando a autora conclui então, apontando que os valores democráticos instituídos pela nova construção social e política do país, dada pela Constituição de 1988, no que se refere à seguridade social, concebe-o como descentralizado, de modo a garantir maior eficácia das políticas sociais de amparo aos direitos dos trabalhadores assalariados e classes menos favorecidas economicamente.

\footnotetext{
${ }^{3}$ DRAIBE, S. M. Qualidade de vida e reformas de programas sociais: o Brasil no cenário latino-americano. Lua nova, São Paulo, Cedec, n. 31, p. 05-46, 1993.

${ }^{4}$ ESPING-ANDERSEN, G. The three worlds of welfare capitalism. Princeton: University Press, 1980.
} 


\section{Considerações finais: ponderações, críticas e indicações}

De forma detalhada e minuciosa, Cohn apresenta um retrato constitutivo da história de um fenômeno político, cultural, econômico e financeiro de nosso país, aspecto que no atual cenário da nação, tem sido bastante trazido a cena, uma vez que concorrem diferentes propostas e discussões de mudanças e de alterações na legislação trabalhista do país, fato que afeta diretamente o trabalhador assalariado brasileiro.

Desse modo, podemos considerar que a discussão apresentada pela autora, no ano de 1995, é bastante fecunda para o cenário atual, com frutos bastante promissores para que se pense o pensar e o fazer político no atual cenário, considerando-se a necessidade de assumimos, a partir do papel social que ocupamos, uma postura ideologicamente marcada, como campo ou lugar para discutir problemas e tensões que impactam a construção e desenvolvimento social de uma nação.

Podemos dizer que a leitura crítico-analítico do artigo, permite uma compreensão dos variados percalços que a previdência social passou, desde seu surgimento até a maturidade assumida nas últimas décadas, quando percebemos a importância e a dimensão de sua abrangência na configuração social do país, e, sobretudo, na garantia dos direitos de cidadania individual do trabalhador.

É um texto curto, no entanto, de leitura rica e profunda, que merece destaque e análise por estudiosos de diversas áreas, em cursos de graduação e pós-graduação, que se destinem a formação de profissionais que trabalhem com essa área. Desse modo, apontamos especialmente, para diferentes agentes científicos no campo das ciências humanas, sociais e aplicadas, preocupados diretamente com as questões sociais, a fim de que, de modo conjunto, possamos trabalhar e contribuir para o reconhecimento e a valorização dos direitos trabalhistas no Brasil.

Assim, tal como apontado por Cohn, citada na epígrafe desta resenha, de alguma maneira, precisamos enfrentar o desafio de contribuir para uma reflexão crítica e transformadora de "um novo padrão de solidariedade social”. Nesse caso, a história constitui um espelho necessário, a fim de delinear nossa tomada de partido hoje e contribuir para a redefinição de velhas questões que se revestem em um debate sempre atual, dado o caráter cíclico dos acontecimentos sociais. 